\title{
CAPACIDADES DINÂMICAS E CAPITAL SOCIAL ORGANIZACIONAL: UM ESTUDO EXPLORATÓRIO EM AMBIENTE DE INCUBADORA E PARQUE TECNOLÓGICO
}

\author{
DYNAMIC CAPABILITIES AND ORGANIZATIONAL SOCIAL \\ CAPITAL: AN EXPLORATORY STUDY IN THE ENVIRONMENT \\ OF INCUBATOR AND TECHNOLOGY PARK
}

\author{
Data de submissão: 27-09-2013 \\ Aceite: 19-05-2014 \\ Vilmar Antonio Gonçalves Tondolo ${ }^{1}$ \\ Rosana Da Rosa Portella Tondolo ${ }^{2}$ \\ Daniel Pedro Puffal ${ }^{3}$ \\ Cláudia Cristina Bitencourt ${ }^{4}$
}

\section{RESUMO}

Os parques tecnológicos e as incubadoras tecnológicas têm sido utilizados como forma de implementação de políticas públicas para o desenvolvimento de inovação e empreendedorismo. Nesse sentido, o objetivo deste estudo é compreender a relação entre Capacidades Dinâmicas (CDs) e Capital Social Organizacional (CSO) no ambiente de incubadora e parque tecnológico. Em relação ao método, trata-se de um estudo de caso exploratório e qualitativo. Os dados foram coletados por meio de entrevistas semiestruturadas e analisados com base na análise de conteúdo. Quanto aos resultados, foi possível identificar a relação entre as CDs e o CSO, com destaque ao desenvolvimento de recursos e de capacidades via laços sociais e ao papel da Associação de Desenvolvimento Tecnológico do Vale (VALETEC) e da Incubadora Tecnológica da Feevale (ITEF) como agentes de promoção de interação social. Tais achados sugerem que a trajetória tem o papel de potencializar os benefícios que as empresas podem obter via CSO.

Palavras-chave: Capacidades Dinâmicas. Capital Social Organizacional. Parques e incubadoras tecnológicas.

\footnotetext{
${ }^{1}$ Possui graduação em Administração de Empresas pela Universidade Federal do Rio Grande, FURG, mestrado em Administração de Empresas pela Universidade do Vale do Rio dos Sinos, UNISINOS e doutorado em Administração pela Universidade do Vale do Rio dos Sinos, UNISINOS. Caxias do Sul. Rio Grande do Sul. Brasil. E-mail: vtondolo@gmail.com

${ }^{2}$ Possui graduação em Ciências Contábeis pela Universidade de Caxias do Sul, UCS, mestrado em Administração pela Universidade de Caxias do Sul, UCS e doutorado em Administração pela Universidade do Vale do Rio dos Sinos, UNISINOS. Passo Fundo. Rio Grande do Sul. Brasil. E-mail: rosanatondolo@gmail.com

${ }^{3}$ Possui graduação em Administração de Empresas pela Universidade do Vale do Rio dos Sinos, UNISINOS, mestrado em Administração pela Universidade do Vale do Rio dos Sinos, UNISINOS e doutorado em Administração pela Universidade do Vale do Rio dos Sinos, UNISINOS. São Leopoldo. Rio Grande do Sul. Brasil. E-mail: DPUFFAL@unisinos.br

${ }^{4}$ Possui graduação em Administração de Empresas pela Pontifícia Universidade Católica do Rio Grande do Sul, PUCRS, mestrado em Administração pela Universidade Federal do Rio Grande do Sul, UFRGS, doutorado em Business pela The University of Queensland, UQ, Austrália e doutorado em Administração pela Universidade Federal do Rio Grande do Sul, UFRGS. São Leopoldo. Rio Grande do Sul. Brasil. E-mail: claucbitencourt@gmail.com
} 


\begin{abstract}
Technology parks and technology incubators have been used as a way of implementation of public policies for the development of innovation and entrepreneurship. Accordingly, this study aims to comprehend the relationship between Dynamic Capabilities (DCS) and Organizational Social Capital (OSC) in the environment of incubator and technology park. Regarding study method, this is a qualitative and exploratory case study. Data were collected through semi-structured interviews and analyzed based on content analysis. As results, it was possible to identify the relationship between the CSO and $C D$ s, especially the development of resources and capabilities via social ties and the role of Valetec and ITEF as promoting social interaction. The results suggest that the trajectory has the role of enhancing the benefits that businesses can obtain through CSO.
\end{abstract}

Keywords: Dynamic Capabilities. Organizational Social Capital. Technology parks and incubators.

\title{
1 INTRODUÇÃO
}

Desenvolver um ambiente de empreendedorismo, inovação e desempenho organizacional tem sido uma política governamental para o estímulo ao crescimento de diversos setores produtivos, em especial aos de tecnologia. Diante desse contexto, o estado do Rio Grande do Sul tem estimulado a instalação de parques tecnológicos por meio de políticas de promoção e fomento, tais como o RS Tecnópole. Atualmente, no Rio Grande do Sul, existem três parques tecnológicos instalados. Um deles é o Parque Tecnológico do Vale dos Sinos, administrado pela Associação de Desenvolvimento Tecnológico do Vale (VALETEC), a qual é objeto deste estudo (SCIT, 2013).

Os parques tecnológicos são vistos como ambientes propícios ao desenvolvimento tecnológico, que apresentam infraestrutura adequada e trabalham com programas que estimulam a sinergia entre o poder público, o meio empresarial e a academia. Em geral, esses ambientes abarcam incubadoras e condomínios de empresas de base tecnológica, sendo, como destacam Lobosco, Moares e Maccari (2011), centrais para o desenvolvimento da competitividade das organizações e para o desenvolvimento tecnológico do país. As incubadoras e os parques tecnológicos correspondem, respectivamente, ao sexto e sétimo mecanismos de interação mais presentes entre universidade e empresa, sendo essenciais para o desenvolvimento de inovação e de tecnologia (SILVA; GIULIANI, 2009).

Compreende-se que, para determinada oportunidade tornar-se um bem ou serviço, a empresa deve desenvolver capacidades internas em termos tanto de processos produtivos quanto de gestão. Tal desenvolvimento de capacidades internas é papel das Capacidades Dinâmicas (CDs). No entanto, os recursos e as capacidades, bem como a identificação de novas oportunidades, podem ser acessados no ambiente externo por meio do Capital Social Organizacional (CSO). Nesse sentido, o desenvolvimento de CDs e CSO é fundamental para as empresas de base tecnológica, uma vez que, por seu intermédio, as organizações acessam recursos e capacidades necessárias para transformar oportunidades em negócios.

Nessa perspectiva, as CDs são definidas como "a capacidade da empresa em integrar, construir e reconfigurar competências internas e externas para lidar com ambientes em rápida mudança" (TEECE; PISANO; SHUEN, 1997, p. 516). Na lógica das CDs, o desenvolvimento de recursos e capacidades é interno às organizações, não eliminando, entretanto, a necessidade de acessar recursos e capacidades via ambiente externo.

A esse respeito, Eisenhardt e Martin (2000) destacam que os processos internos são as fontes das CDs. A trajetória da organização leva ao acúmulo de conhecimento capaz de gerar novas rotinas e processos ao longo do tempo (SAPIENZA et al., 2006). Nesse contexto, destacam-se, 
também, os processos organizacionais internos, como a aprendizagem organizacional e a inovação (MCGUINNESS; MORGAN, 2000).

O conceito de CSO surge com os estudos de Nahapiet e Ghoshal (1998), quando esses autores apresentam um framework aproximando o capital social do capital intelectual no contexto organizacional. Nesse estudo, o CSO é visto a partir de três dimensões: estrutural, cognitiva e relacional. O CSO, diferentemente do capital humano, representa o valor dos recursos envolvidos na avaliação de uma rede de relações (NAHAPIET; GHOSHAL, 1998). Nesse sentido, diversas pesquisas futuras tenderão a relacionar a motivação pessoal com o processo de elaboração da estratégia e o CSO ou, ainda, a investigar como o capital social impacta a efetividade dos diferentes modelos de estratégia (DESS; LUMPKIN, 2006).

Os relacionamentos, assim como os laços formados pelo CSO, podem ser vistos como fonte de desenvolvimento de recursos e capacidades pelas CDs (ALSOS et al., 2007; EISENHARDT; MARTIN, 2000; BLYLER; COFF, 2003). Assim sendo, é possível perceber que a aproximação entre CSO e CDs pode ser concebida pela lógica dos recursos e das capacidades.

Diante do exposto, este estudo tem como objetivo compreender a relação entre CDs e CSO no ambiente de incubadora e parque tecnológico. Para isso, além desta parte introdutória, o presente estudo está organizado nas seguintes seções: revisão de literatura, procedimentos metodológicos, análise dos dados, considerações finais e referências.

\section{FUNDAMENTAÇÃO TEÓRICA}

Tendo em vista o objetivo deste estudo, são abordados, nesta seção, os seguintes elementos teóricos: CDs, CSO e aproximação entre CDs e CSO.

\subsection{Capacidades Dinâmicas}

O termo CDs diz respeito a dois argumentos centrais. O primeiro refere-se ao papel da gestão de lidar com o ambiente competitivo. Já o segundo refere-se ao caráter de contínua mudança no ambiente competitivo, requisitando esforço da gestão em lidar com essa mudança (TEECE; PISANO; SHUEN, 1997). Portanto, o conceito de CDs defende que as organizações obtêm vantagem competitiva por meio do desenvolvimento contínuo de recursos e capacidades (MAKADOK, 2001).

Ao realizar uma breve análise histórica, verifica-se que as CDs emergiram das abordagens teóricas sobre a exploração e o desenvolvimento interno e externo de recursos e capacidades específicas da própria organização (PENROSE, 1962) e da ênfase no desenvolvimento de capacidades necessárias para adaptação contínua às mudanças no ambiente competitivo (HENDERSON, 1994; TEECE; 2007). Nesse sentido, as CDs passaram a reconhecer o papel da exploração e renovação do conjunto de recursos e das capacidades organizacionais ao longo do tempo. Assim, a teoria das CDs começou a considerar o papel da exploração do estoque atual de recursos e capacidades organizacionais.

Um dos principais resultados das CDs é criar, renovar ou integrar recursos, ativos, capacidades, competências e rotinas, habilitando as organizações a acompanharem as mudanças no ambiente competitivo. Nesse sentido, "o desenvolvimento de capacidades como resultado das capacidades dinâmicas ao longo do tempo é frequentemente discutido e evidenciado na pesquisa empírica" (WANG; AHMED, 2007, p. 40).

Esse resultado é obtido por mecanismos de aprendizagem (TEECE; PISANO; SHUEN, 1997; EISENHARDT; MARTIN, 2000; ZOLLO; WINTER, 2002; TEECE, 2007; AMBROSINI; BOWMAN, 
2009), tais como coordenação/integração e reconfiguração/transformação dos recursos e das capacidades organizacionais; pelo comprometimento organizacional em desenvolver ativos, tangíveis ou intangíveis (TEECE; PISANO; SHUEN, 1997; ZOTT, 2003), como, por exemplo, o desenvolvimento de fornecedores e de ativos dedicados ${ }^{5}$; ou, ainda, pelo papel da trajetória das organizações (TEECE; PISANO; SHUEN, 1997). Nesse sentido, o que a organização é capaz de realizar hoje e no futuro depende de que ela desenvolveu ao longo de sua trajetória.

Além disso, destacam-se dois processos centrais que descrevem o cerne das CDs, o sensing e o seizing. O sensing remete à identificação de uma oportunidade (HODGKINSON; HEALEY, 2011; TEECE, 2012), sendo definido como a "habilidade da organização em detectar com exatidão mudanças em seu ambiente competitivo, incluindo mudanças potenciais na tecnologia, competição, clientes e regulação" (HARRELD; O'REILLY III; TUSHMAN, 2007, p. 24).

Já o seizing diz respeito ao conjunto de recursos e capacidades mobilizados para explorar a oportunidade identificada (HODGKINSON; HEALEY, 2011; TEECE, 2012), consistindo na "habilidade da organização em agir sobre essas oportunidades e ameaças, para ser capaz de aproveitá-las, reconfigurando os ativos tangíveis e intangíveis para enfrentar novos desafios" (HARRELD; O'REILLY III; TUSHMAN, 2007, p. 25).

Nesse sentido, as capacidades dinâmicas são vistas como propulsoras para o sucesso dos negócios, uma vez que, por meio do desenvolvimento das CDs, as organizações aprimoram capacidades internas e externas à organização, contribuindo, assim, para a obtenção e apropriação de recursos. $\mathrm{O}$ desenvolvimento das CDs influencia a forma como as organizações competem e pode estar diretamente ligado à vantagem competitiva.

\subsection{Capital Social Organizacional}

O CSO surge a partir do estudo de Nahapiet e Ghoshal (1998), quando os autores apresentam o capital social a partir de três dimensões: estrutural, cognitiva e relacional. A dimensão estrutural é definida como a localização do ator e os contatos que este possui em uma estrutura social, proporcionando algumas vantagens para o próprio ator. Tais vantagens são obtidas quando os indivíduos se utilizam de certas posições no trabalho, informações ou acesso a recursos específicos (NAHAPIET; GHOSHAL, 1998; TSAl; GHOSHAL, 1998). A dimensão cognitiva, por sua vez, refere-se aos recursos que são providos por representações, interpretações e sistemas de significado, os quais são associados aos atores envolvidos (NAHAPIET; GHOSHAL, 1998). Já a dimensão relacional descreve o tipo de relações desenvolvidas entre os atores, referindo-se aos ativos criados e potencializados por meio dos relacionamentos, que promovem confiança, credibilidade, normas, sanções, expectativas e obrigações nas relações (NAHAPIET; GHOSHAL, 1998).

Neste estudo, o CSO é visto a partir dessas três dimensões (estrutural, cognitiva e relacional), que também são utilizadas por diversos estudos como base para a mensuração do capital social. Esse é o caso das pesquisas de Acquah (2007), Bolino, Turnley e Bloodgood (2002), Inkpen e Tsang (2005), Moran (2005), Tsai e Ghoshal (1998) e Tsai (2000).

Ao partir do entendimento de que capital social é a soma dos recursos reais e potenciais envolvidos, disponíveis e derivados da rede de relacionamentos mantidas pelo indivíduo ou pela unidade social (NAHAPIET; GHOSHAL, 1998), presume-se a relevância de definir o que é CSO para a corrente literatura. O CSO reflete a qualidade efetiva das relações internas da organização, a preocupação partilhada por objetivos comuns e o grau de coesão entre os colaboradores (PASTORIZA; ARIÑO; RICART, 2009).

Além disso, o CSO pode ser visto como o recurso que reflete o caráter das relações sociais

${ }^{5}$ Ativos dedicados são uma das formas de ativos específicos. Como definem Besanko et al. (2006, p. 145), "um ativo dedicado é um investimento em uma fábrica ou equipamento para satisfazer um comprador em particular". 
com as organizações, sendo realizado pelos membros das organizações que possuem uma orientação a objetivos coletivos e uma visão compartilhada e criando valor a partir da ação coletiva (LEANA; VAN BUREN, 1999). Assim, o CSO pode beneficiar ambos os níveis organizacionais, internos e externos, criando valor para os stakeholders e aumentando a habilidade dos colaboradores, por exemplo. Nesse sentido, o CSO consiste nos recursos que as organizações obtêm por meio de suas relações com outras organizações (ZAHRA, 2010), podendo ser interpretado, ainda, como a boa vontade de disponibilizar recursos a um ator por meio de suas recíprocas relações de confiança (ARREGLE et al., 2007).

Diante dessa discussão, neste estudo, o CSO é considerado um componente essencial das capacidades dinâmicas que habilita a gestão de recursos (BLYLER; COFF, 2003). Ao buscar um melhor entendimento dos recursos nesse cenário, o CSO pode prover diferentes tipos de vantagens para as organizações, tais como: informações, conhecimento, tecnologia, capital financeiro, posicionamento em redes e relações com atores estratégicos (ARREGLE et al., 2007). No entanto, mesmo conhecendo os aspectos positivos do CSO, questiona-se: o que conduz uma organização a ceder ou compartilhar seus recursos?

Alguns autores enfatizam que os recursos só podem ser compartilhados ou cedidos a partir de relações de confiança mútua e de ambientes em que os objetivos coletivos são considerados prioridade e as organizações são capazes de cooperar e colaborar com as demais organizações (LEANA; VAN BUREN, 1999). Seguindo essa lógica, o CSO apresenta basicamente dois componentes: associabilidade e confiança. A associabilidade é definida como a boa vontade e habilidade dos participantes de uma organização de abdicar objetivos individuais e ações associadas em virtude de objetivos e ações coletivas. Por esse motivo, a associabilidade é vista como algo diferente da sociabilidade, uma vez que a associabilidade requer mais do que a simples interdependência (LEANA; VAN BUREN, 1999). Já a confiança tem sido vista não somente como um antecedente, mas também como um resultado da ação coletiva. Nesse sentido, para as ações coletivas existirem, é necessário confiança entre os indivíduos. Também vale ressaltar que, nas ações coletivas que obtiveram êxito, a confiança foi observada como um elemento-chave (LEANA; VAN BUREN, 1999).

Segundo a literatura vigente, percebe-se que o CSO atua como facilitador na criação do capital intelectual e que empresas com níveis mais elevados de CSO podem deter uma vantagem competitiva, considerando certos limites, na criação e no compartilhamento do capital intelectual (NAHAPIET; GHOSHAL, 1998). Diante disso, considera-se que o CSO pode afetar positivamente as atividades internas e externas da organização (ARREGLE et al., 2007).

A esse respeito, Pastoriza, Ariño e Ricart (2008) exploram a influência do CSO no desempenho financeiro das firmas. Os resultados encontrados por esses autores são complementares aos de outros estudos, tais como o de Leana e Pil (2006) e Tsai e Ghoshal (1998), indicando que os resultados são robustos e podem ser generalizados ao nível organizacional (PASTORIZA; ARIÑO; RICART, 2008).

\subsection{A Visão Baseada em Recurso como aproximação entre as teorias de Capacidades Dinâmicas e Capital Social Organizacional}

Na lógica da Visão Baseada em Recurso (VBR), uma organização é vista como um conjunto de recursos tangíveis e intangíveis. A diferença entre as organizações advém da experiência baseada na trajetória, bem como dos ativos consolidados, das habilidades e da cultura organizacional. Tais ativos e capacidades determinam a eficiência dos resultados e a eficácia da organização. Nessa visão, a vantagem competitiva consolida-se a partir dos recursos valiosos, únicos e difíceis de imitar (COLLIS; MONTGOMERY, 1995; BARNEY, 1991; 2001). O entendimento 
da vantagem competitiva pela lógica dos recursos e das capacidades possui duas vias: (i) a acumulação e gestão de ativos intangíveis e (ii) as teorias de competências e diversificação corporativa (BARNEY; ARIKAN, 2005).

Na literatura sobre capital social, são encontrados diferentes posicionamentos no que tange à aplicação e às potencialidades do CSO. Este tem sido rotineiramente abordado pela literatura à luz da VBR. Nesse sentido, vale ressaltar o papel da VBR na estratégia organizacional, uma vez que organizações que dispõem de recursos valiosos, raros, difíceis de imitar e insubstituíveis estão mais propensas a obterem melhores resultados (BARNEY, 1991). Para Barney (1991), os recursos das organizações compreendem o conjunto de capacidades, processos organizacionais, atributos, informação e conhecimento que são controlados pela organização e possibilitam a implementação de suas estratégias.

Já na visão de Craig e Grant (1999), o conceito de recursos é diferente do conceito de capacidades, uma vez que os recursos são os patrimônios específicos da organização, enquanto que as capacidades são o que a organização é capaz de fazer dispondo desses recursos. As capacidades consistem, portanto, na habilidade da organização de disponibilizar recursos a fim de atingir um objetivo específico (WANG; AHMED, 2007).

Em um ambiente competitivo, a VBR enfatiza que as organizações que detêm recursos ou capacidades valiosos, raros, difíceis de imitar e insubstituíveis possuem vantagem sobre suas competidoras (BOLINO, TURNLEY, BLOODGOOD, 2002). Nesse sentido, um importante componente da vantagem competitiva reside no capital social das organizações (EDELMAN et al., 2004), já que o CSO é visto como um "recurso que reflete o caráter das relações sociais com a firma" (LEANA; VAN BUREN, 1999, p. 538). Já pela lógica das CDs, as organizações obtêm um desempenho superior por meio do desenvolvimento de recursos e capacidades ao longo do tempo (MAKADOK, 2001; SAPIENZA et al., 2006; AMBRONISI; BOWMAN, 2009).

A literatura especializada sugere que o capital social é um recurso valioso, porque pode reduzir os custos de transação por meio da economia nos custos de informação e transação (NAHAPIET; GHOSHAL, 1998). O CSO é um importante recurso intangível que pode levar anos para ser desenvolvido e requer criatividade na hora de seu retorno, uma vez que pode ser potencializado, tornando, assim, seu valor mais duradouro (ZAHRA, 2010). De acordo com Nahapiet e Ghoshal (1998), as diferenças de desempenho encontradas entre as firmas podem ser explicadas pelas diferenças nas habilidades para criar e explorar o capital social. De forma semelhante, um argumento central das CDs é a capacidade da organização em desenvolver capacidades de alto nível por meio de sua trajetória, alavancando e/ou sustentando o desempenho superior (HARRELD; O'REILLY III; TUSHMAN, 2007).

O CSO suporta a firma por meio do incremento da disponibilidade de recursos, os quais são perceptíveis por meio de informação, tecnologia, conhecimento, capital financeiro e distribuição de redes. Também pode ser notado, inclusive, em relações consideradas um pouco mais críticas por parte das firmas, como, por exemplo, em relações que envolvem o governo e os mercados estrangeiros ou, ainda, em relações diplomáticas (ARREGLE et al., 2007). Por isso, o CSO beneficia a firma tanto no acesso ao recurso externo quanto na facilitação dos processos internos (ARREGLE et al., 2007; SIRMON; HITT; IRELAND, 2007). Nesse sentido, as CDs também destacam a habilidade da empresa em construir, integrar ou reconfigurar capacidades operacionais, contribuindo para o desempenho das capacidades operacionais da organização (HELFAT; PETERAF, 2003).

Diante disso, Arregle et al. (2007) ressaltam a importância da heterogeneidade dos grupos internos nas firmas e das características dos grupos dominantes no desenvolvimento de capital social. O CSO constitui uma propriedade coletiva distintiva que deve ser mediada pelos 
indivíduos, sendo uma única forma organizacional (PENNINGS; LEE, 1998). Assim, "o capital social é ainda mais exclusivo e difícil de apropriar do que outros tipos de ativos, uma vez que depende do envolvimento contínuo de duas ou mais partes" (PENNINGS; LEE, 1998, p. 3).

Os relacionamentos também são vistos como fonte de desenvolvimento de recursos e capacidades pelas CDs (ALSOS et al., 2007; EISENHARDT; MARTIN, 2000), bem como os laços formados pelo CSO (BLYLER; COFF, 2003). Nesse sentido, é possível perceber que a aproximação entre CSO e CDs pode ser concebida pela lógica dos recursos e das capacidades.

\section{PROCEDIMENTOS METODOLÓGICOS}

Este trabalho teve como objetivo compreender a relação entre CDs e CSO no ambiente de incubadora e parque tecnológico. Para tal, foi desenvolvido um estudo de caso exploratório com abordagem qualitativa no parque tecnológico da VALETEC e na incubadora ITEF.

A técnica de coleta de dados utilizada foi a aplicação de um roteiro de entrevista semiestruturada com gestores da VALETEC, da ITEF e das empresas associadas e incubadas. Todas as entrevistas foram gravadas e transcritas para posterior análise. Ao todo, foram realizadas sete entrevistas com duração média de 50 a 90 minutos.

O Quadro 1, exposto a seguir, apresenta um sumário do perfil dos gestores entrevistados. Para preservar a exposição das informações pessoais dos gestores, um codinome foi atribuído a cada um deles. Cabe destacar que foram coletados dados por parte de gestores da VALETEC e da ITEF, bem como dos gestores de empresas incubadas na ITEF e associadas à VALETEC.

Segundo Eisenhardt (1989), a análise dos dados é central para o desenvolvimento de teoria, sendo o mais desafiador e esquemático estágio da pesquisa. Em outras palavras, o desafio é fazer os dados gerarem senso (CRESWELL, 2003). Os dados foram analisados com base na análise de conteúdo, inspirando-se em Flick (2004) e Creswell (2003) e considerando os seguintes passos: (i) preparação da organização dos dados por meio das transcrições de entrevistas e das notas de campo; (ii) leitura intensiva dos dados, a fim de identificar o seu significado; (iii) detalhamento do material, que envolve a codificação e classificação de acordo com as categorias de análise; (iv) descrição baseada em codificação, visando à descrição do objeto, seguindo as categorias e o material coletado; ( $v$ ) utilização das evidências, que envolve o uso das evidências coletadas para expressar as conclusões do estudo; e (vi) interpretação do significado dos dados, envolvendo o entendimento do pesquisador acerca dos dados coletados, comparando-os com a literatura estabelecida (confirmação ou divergência.

\begin{tabular}{|c|c|c|c|c|}
\hline Codinome & $\begin{array}{l}\text { Experiência } \\
\text { profissional }\end{array}$ & $\begin{array}{c}\text { Área de atuação } \\
\text { da empresa }\end{array}$ & $\begin{array}{l}\text { Tempo de atua- } \\
\text { ção da empresa }\end{array}$ & Categorização \\
\hline Gestor VALETEC & 12 anos & Parque tecnológico & 15 anos & Associação \\
\hline Gestor ITEF & 15 anos & Incubadora tecnológica & 14 anos & Incubadora \\
\hline Gestor marcas & 7 anos & Branding e marketing & 1 ano & Incubada \\
\hline Gestor software & 10 anos & $\begin{array}{l}\text { Desenvolvimento de } \\
\text { software }\end{array}$ & 1 ano & Incubada \\
\hline Gestor aferição & 25 anos & Aferição de instrumentos & 17 anos & $\begin{array}{l}\text { Graduada - asso- } \\
\text { ciada VALETEC }\end{array}$ \\
\hline Gestor cosméticos & 30 anos & $\begin{array}{c}\text { Cosméticos e cuidados } \\
\text { pessoais }\end{array}$ & 6 anos & $\begin{array}{c}\text { Graduada - asso- } \\
\text { ciada VALETEC }\end{array}$ \\
\hline Gestor peças & 18 anos & Peças de precisão & 8 anos & $\begin{array}{c}\text { Graduada - asso- } \\
\text { ciada VALETEC }\end{array}$ \\
\hline
\end{tabular}

Quadro 1 - Sumário das características dos gestores e das empresas 
Fonte: dados da pesquisa

As categorias de análise foram baseadas no referencial teórico, orientando a codificação inicial por meio de conceitos (GIBBS, 2009). Dessa forma, tais categorias foram estruturadas em três grupos: o grupo geral refere-se ao objetivo e ao papel do VALETEC e da ITEF, visando à maior compreensão dessas organizações; o grupo Capital Social Organizacional é formado pelas categorias interação e relacionamentos; e o grupo das Capacidades Dinâmicas é constituído pelas categorias recursos e capacidades desenvolvidas e identificação e exploração de oportunidades desenvolvidas (sensing e seizing).

Destaca-se que, no aspecto referente à validação, houve a utilização de protocolos para o desenvolvimento e a formalização do estudo de caso, que teve como base o referencial teórico previamente definido, com o objetivo de uniformizar e sistematizar a tarefa de observação e análise, aumentando a confiabilidade do estudo (validade interna). Também houve o cuidado de utilizar múltiplas fontes de evidências, buscando a triangulação dos dados, por meio do cruzamento de diferentes fontes para o estudo do mesmo objeto, como forma de validar e verificar sua consistência (STAKE, 1998; YIN, 2001). Além disso, a análise foi operacionalizada por meio do software $\mathrm{Nvivo}^{\circledR}$ versão 9.

Quanto à validade externa, acredita-se que seja possível adotar o método da generalização analítica (YIN, 2001), no qual uma teoria previamente desenvolvida serve de quadro de referência para a comparação entre resultados empíricos obtidos. Portanto, sugerem-se novos estudos que possam avançar na discussão proposta neste momento.

\section{ANÁLISE DOS DADOS}

A VALETEC foi criada em 1998 no Vale do Rio dos Sinos, no estado do Rio Grande do Sul. Os princípios norteadores de sua criação foram a inovação, o desenvolvimento tecnológico e o empreendedorismo. O objetivo geral da VALETEC é promover ações visando ao desenvolvimento tecnológico da região na qual está inserida, buscando: a integração regional, o incentivo ao empreendedorismo, a criação e o desenvolvimento de empresas e a pesquisa.

A VALETEC está capacitada para administrar ambientes de inovação tecnológica, como incubadoras, condomínios empresariais, parques e polos tecnológicos, além de gerir outras ações de interesse das suas instituições integrantes. A VALETEC apoia empreendedores com informações, programas de formação empreendedora, pré-incubação, incubação de empresas e spin-offs, por meio de suas instituições associadas e parceiras, como, por exemplo, da ITEF e da Incubadora Tecnológica da Fundação Liberato (ITEL).

A VALETEC visa articular atividades de interesse dos seus associados, empreendendo ações como: a captação de investidores, o desenvolvimento e planejamento de infraestrutura de transporte, a identificação de locais para instalação de empresas, a contribuição em processos de obtenção de licenças (ambientais, por exemplo) nos ambientes administrados pela VALETEC, a proposição de legislações de apoio ao desenvolvimento econômico regional, a identificação de benefícios para empresas, o desenvolvimento de programas que atendam às necessidades de suas empresas associadas e a articulação entre os diversos níveis governamentais, instituições de ensino e pesquisa, entidades e empresas, dentre outros.

Atualmente, a VALETEC possui 18 empresas instaladas no parque tecnológico e 60 empresas associadas. Já a ITEF conta com oito empresas em processo de incubação. Tendo em vista o alcance dos objetivos propostos neste estudo, a análise dos dados está estruturada na percepção dos gestores da VALETEC e da ITEF e na percepção dos gestores de empresas associadas e 
incubadas.

\subsection{Percepção dos gestores da VALETEC e da ITEF}

A VALETEC é percebida pela sua gestão como indutora do processo de interação entre universidade, empresa e poder público. Essa interação é promovida por meio da geração de um ambiente em que os agentes e as empresas possam interagir. Ações tais como a utilização de recursos estatais, a instalação de estruturas de apoio e as consultorias em gestão, via universidade, são exemplos de promoções de interações entre as organizações e seus ambientes interno e externo. Nesse sentido, a VALETEC busca desenvolver um espaço propício para que as empresas interajam, desenvolvendo recursos que possam ser compartilhados entre as empresas e os demais agentes, como governo e universidades. Conforme destaca o gestor entrevistado da VALETEC:

Então a gente não tem como obrigar que as empresas se envolvam, mas a gente tem como fomentar isso criando um ambiente para que essa interação ocorra. Então a gente busca, usando recursos do governo do estado, criando aqui através das nossas competências, uma estrutura que possa ser usada tanto por universidade como por empresas, fazendo então laboratório, equipar com seus dados de uso compartilhado, sempre focando na necessidade tanto da universidade quanto das empresas.

A ITEF também tem papel de fomentar a interação, sendo vista como articuladora nesse processo. Como destacado pelo seu gestor, as empresas, na maioria das vezes, não têm conhecimento dos caminhos para acessar tanto a universidade quanto os agentes governamentais, ficando a cargo da ITEF essa articulação. Nessa ótica, a ITEF visa promover a interação entre a universidade e os agentes governamentais, como se observa no relato a seguir:

O papel é atrair essas informações para dentro da incubadora, para o empresário poder dentro de alguma forma de aquilo que ele trabalha, vai estar se beneficiando, buscando conhecimento e desenvolvimento do seu produto dentro da universidade, buscando informação e aplicando a legislação adequada dentro da parte do governo, ou recursos do governo para poder se fortalecer. O papel da incubadora esta no meio, eu vejo a incubadora ali é o articulador entre todas essas ações (Gestor ITEF).

A intenção dessa interação é gerar competências que possam ser compartilhadas pelas empresas. Nesse sentido, a interação e os relacionamentos entre as empresas são vistos como formas de desenvolvimento de competências que possam ser compartilhadas, complementando as competências das empresas. No entanto, essa interação frequentemente é limitada por barreiras de ordem cultural. Há receio por parte de certas empresas, em geral mais tradicionais, de compartilhar informações e conhecimentos, o que não é tão evidente, segundo relato, por parte das empresas mais novas, as quais estão mais abertas à troca. Essa falta de abertura impede que o resultado da interação seja mais expressivo, como se destaca no relato transcrito a seguir:

O que a gente quer fazer com isso é que, através desses relacionamentos, criem produtos, criem processos em parceria, através das competências complementares das empresas que a gente consiga gerar mais valor. $\mathrm{O}$ que é um paradigma às vezes cultural [...] Aqui a gente tem ainda muito esse viés de é meu produto, fui eu que desenvolvi, não abro para ninguém, e é um segredo industrial. As empresas novas elas são muito mais abertas a trocar informações [...] é muito mais na confiança. Então essa mudança de cultura vem acontecendo, claro que a gente gostaria ainda de quebrar isso nas empresas mais antigas, que têm mais capacidade, mais fôlego, para trabalhar com esse desenvolvimento de tecnologia, que exigiria um investimento maior (Gestor VALETEC). 
A VALETEC promove encontros mensais para fomentar a interação entre as empresas. Nesses eventos, são discutidos assuntos de interesse gerais voltados à inovação. Foram citados pelo gestor entrevistado da VALETEC dois eventos em especial: um com agentes de inovação da Financiadora de Estudos e Projetos (FINEP), e uma palestra sobre capital empreendedor. Também foi destacado pelo mesmo gestor o uso do portal da inovação, como ferramenta de fomento à interação entre as empresas. Da mesma forma, a ITEF vale-se de encontros formais, realizados mensalmente, visando adensar a interação e o relacionamento entre as incubadas.

Mesmo o foco sendo o apoio na identificação de oportunidades, a VALETEC e a ITEF também visam desenvolver a capacitação das empresas associadas e das incubadas. Em geral, esse apoio ao desenvolvimento interno das empresas é voltado para a capacidade de gestão. $O$ gestor entrevistado da VALETEC destacou, por exemplo, o desenvolvimento ocorrido em termos de gestão de processos. Por meio de recursos financeiros do governo, professores da universidade ministraram um curso de capacitação em gestão de processos. O objetivo é instrumentalizar as empresas no que tange ao uso de recursos para projetos de desenvolvimento, visando explorar de forma mais eficiente as oportunidades identificadas, como pode ser observado no seguinte relato:

A capacitação e formação são fundamentais nesse processo [...] eu tenho que saber transformar isso, saber fazer essa leitura do que está acontecendo, identificar as oportunidades, como no caso foi feito, e desenvolver as habilidades técnicas para fazer aquilo se tornar um produto [...] eu preciso ter a formação para saber como tecnicamente eu consigo criar o produto que vai atender aquela necessidade que eu identifiquei na "minha abertura para o mundo". Daí as empresas têm que se voltar para si mesmas um pouco e trabalhar essa questão (Gestor VALETEC).

Como destacam os gestores entrevistados da VALETEC e ITEF, não basta identificar uma oportunidade, pois as empresas necessitam desenvolver um conjunto de capacidades para poder explorar as oportunidades. É interessante notar, ainda, que a interação entre as próprias empresas incubadas pode ser uma fonte de recursos e de capacidades para desenvolver novos negócios. Essas empresas podem acessar suas complementariedades, gerando oportunidades e acesso a recursos via editais, como pode ser observado no seguinte relato:

Eles estão unindo esforços conjuntos, às vezes uma tecnologia a mais, para ter uma empresa estruturada. Então essa experiência de profissionais de outras áreas que se complementam na parte de outros conhecimentos, isso tem fortalecido muito eles também. [...] Os recursos, os editais, isso é algo constante dentro da incubadora [...] tem aqueles editais que é edital para o empresário, que isso às vezes sai oportunidades que buscam aqueles olhares, vou buscar esse edital que eu tenho competência para fazer e desenvolver esse projeto ou outro projeto. Ou, às vezes, as parcerias entre duas empresas em comum buscarem algum serviço ou um novo produto (Gestor ITEF).

Também foi destacado pelo gestor entrevistado da ITEF o caso de empresas que formaram parceria para desenvolver um projeto via edital da FINEP. Além disso, há empresas que fazem trabalhos em conjunto com empresas de fora da ITEF e da VALETEC. No Quadro 2, apresenta-se a síntese das percepções dos gestores da VALETEC e da ITEF, bem como uma relação entre essas percepções e os aspectos teóricos de CSO e CDs. 


\begin{tabular}{|c|c|c|}
\hline \multicolumn{2}{|r|}{ Aspectos observados } & Aspectos teóricos \\
\hline \multirow[t]{2}{*}{ CSO } & $\begin{array}{l}\text { VALETEC e ITEF visam promover um ambiente e } \\
\text { interação entre as empresas por meio de recur- } \\
\text { sos compartilhados e de informação. }\end{array}$ & $\begin{array}{l}\text { Visão compartilhada e relações entre os agen- } \\
\text { tes remetem ao CSO (PASTORIZA; ARIÑO; RI- } \\
\text { CART, 2009). }\end{array}$ \\
\hline & $\begin{array}{l}\text { Encontros formais são meios de promover a in- } \\
\text { teração e o relacionamento entre as empresas. }\end{array}$ & $\begin{array}{l}\text { A rede de relacionamentos e os recursos dela } \\
\text { gerados englobam o capital social (NAHAPIET; } \\
\text { GHOSHAL, 1998). }\end{array}$ \\
\hline CDs & $\begin{array}{l}\text { VALETEC e ITEF visam desenvolver capacidades } \\
\text { para que as empresas possam explorar as opor- } \\
\text { tunidades. }\end{array}$ & $\begin{array}{l}\text { As CDs refletem a habilidade da empresa em } \\
\text { desenvolver recursos e capacidades ao lon- } \\
\text { go do tempo (TEECE; PISANO; SHUEN, 1997; } \\
\text { HELFAT; PETERAF, 2003; HARRELD; O'REILLY III; } \\
\text { TUSHMAN, 2007), remetendo às característi- } \\
\text { cas do sensing e seizing. }\end{array}$ \\
\hline $\begin{array}{l}\text { CSO e } \\
\text { CDs }\end{array}$ & $\begin{array}{l}\text { A interação entre as empresas é vista como fon- } \\
\text { te de recursos e de capacidades complementa- } \\
\text { res. }\end{array}$ & $\begin{array}{l}\text { O CSO pode ser visto como o recurso via rela- } \\
\text { ções sociais e ação coletiva (LEANA; VAN BU- } \\
\text { REN, 1999), promovendo diferentes tipos de } \\
\text { recursos (ARREGLE et al., 2007), ou seja, como } \\
\text { fonte de recursos e de capacidades (ALSOS et } \\
\text { al., 2007; BLYLER; COFF, 2003; EISENHARDT; } \\
\text { MARTIN, 2000) }\end{array}$ \\
\hline
\end{tabular}

Quadro 2: Síntese da percepção dos gestores da VALETEC e da ITEF

Fonte: elaboração própria

De forma particular, no que tange à complementariedade entre CSO e CDs, o desenvolvimento de recursos e de capacidades ao longo do tempo pode ser potencializado pelo CSO, bem como o CSO pode ser visto como um recurso e/ou uma capacidade também desenvolvida pela trajetória das organizações.

\title{
4.2 Percepção dos gestores de incubadas na ITEF e de associadas à VALETEC
}

Um dos pontos centrais destacados pelos gestores das empresas quanto às capacidades foi o desenvolvimento de uma equipe de trabalho e recursos específicos. Foi ressaltada a necessidade de complementar os conhecimentos e as habilidades do empreendedor, isto é, daquela pessoa que vislumbrou o negócio, com competências e capacidades de outros indivíduos. Dessa forma, uma possibilidade de mercado tornou-se um empreendimento, como pode ser destacado no seguinte relato:

\begin{abstract}
Mas, basicamente eu tive que criar internamente capacidade tanto técnica quanto de recursos para que eu não precisasse depender de outros. Quando eu falo isso eu falo pessoal e equipamentos, pessoal era trazer pessoas que tinham conhecimento de design de produto ou de projetos que me auxiliassem, que isso é uma coisa que eu não domino, mas sei que preciso que façam isso, que façam aquilo, e tem gente que faz isso. $E$ também os equipamentos (Gestor peças).
\end{abstract}

Outro ponto central no desenvolvimento de capacidades destacado pelos gestores foi a busca de conhecimento especializado, via formação ou fornecedores. Para o gestor software, por exemplo, "tecnicamente a gente teve que ir em busca de curso e especialização para começar a trabalhar com mobile, que é uma área que a gente não trabalhava antes". Já para o gestor peças, "eu identifiquei que ele é a única empresa do mundo que produz que injeta qualquer [...] então eu busquei nele a expertise para que eu não precisasse desenvolver internamente". Para a empresa cosméticos, o ponto central foi desenvolver capacidades na área comercial. Como destacado pelo gestor, a equipe dominava o processo, mas colocar o produto no mercado foi uma tarefa árdua "que nós tivemos maior dificuldade, tivemos que aprender muito na área comercial, 
nós pecamos muito" (Gestor cosméticos).

Cabe destacar, ainda, a busca por parcerias como fonte de acesso a capacidades necessárias aos negócios, conforme pode ser observado na fala do gestor marcas: "eu faço uma pesquisa com várias pessoas e através de indicação e vou fazendo análise e pesquisas para ver se essas pessoas realmente se encaixam no perfil da empresa. Eu trabalho muito com parceria". A empresa software também forma parcerias para complementar suas capacidades: "ali é uma solução pronta, então eles fazem a especialidade deles, e nós a nossa" (Gestor software). No entanto, é preciso ressaltar que esse processo de desenvolvimento de parcerias foi desenvolvido ao longo do tempo, como se pode observar no seguinte relato:

Eu não me preparei para isso. Se tu me perguntar se eu estudei para coordenar parcerias, coisas do gênero, não. Acho que por isso que algumas vezes eu tive que abrir mão de algumas parcerias que não deram certo, que eu julgava que seriam muito boas pela capacidade que eles têm, mas não fechava com a capacidade dos meus clientes. E aí eu tive que abrir mão delas e ir para outros diferentes, então eu não fiz nada para aprender isso, eu aprendi na amarra, aprendi caindo, aprendi fazendo (Gestor marcas).

Os editais de desenvolvimento de tecnologia foram apontados pelos gestores como uma fonte de desenvolvimento de capacidades. Contudo, conforme o gestor da empresa aferição, é necessário que os empreendedores aprendam como desenvolver projetos para esses editais:

Comecei a estudar melhor essa questão de editais e consegui vislumbrar que ali tem uma porta muito grande aberta de oportunidades. Você está dentro de um parque tecnológico, você está dentro de uma entidade universitária [...], e, quando surge um edital, que é o nosso caso agora, a gente está começando a ver que a questão é entrar para o lado de pesquisa, tem mais que aproveitar. E esses editais contemplam realmente o setor que a gente está visando (Gestor aferição).

No que tange ao CSO, foram observados nos relatos dos gestores das empresas incubadas e associadas aspectos relacionados à interação e aos relacionamentos. Essas interações são providas por práticas formais e informais. $O$ gestor da empresa cosméticos não percebeu relacionamento ou interação, pois, para ele, as relações se limitaram mais ao convívio ou à interação social com os demais empreendedores: "na incubadora e no parque a gente só teve relações de convívio como colegas, comercialmente não" (Gestor cosméticos). Esse aspecto sugere que barreiras podem ser impostas, reduzindo a possibilidade de obter ganhos do CSO.

As interações formadas entre as empresas VALETEC e ITEF vão além da questão social. Como destacado pelos gestores, são realizados encontros formais, nos quais os empreendedores têm a oportunidade de compartilhar experiências e conhecimento, o que possibilita, ainda, que novos negócios via parcerias sejam formados, como pode ser observado nos seguintes relatos:

Começamos a ter reuniões de empresas mensalmente para discutir todas as dificuldades que as empresas tinham, as necessidades que as empresas precisavam suprir, parceiras que precisavam ser executadas, todo o tipo de melhoria que precisava ser executado. [...] hoje quatro empresas daquelas 10 estão no parque da VALETEC (continuam interagindo ali), e a relação ainda com a universidade, essa relação também continua (Gestor aferição).

Há uma interação mensal, que é a reunião que a incubadora proporciona, e tem uma interação anual, que é final de ano, [...] reúne para assuntos profissionais (Gestor marcas).

As interações também emergem pelas características das empresas, geradas de forma espontânea, destacando-se a informalidade nas relações. Para a empresa software, esse proces- 
so ocorre pela personalidade aberta dos empreendedores, como pode ser observado:

Da nossa parte é natural, até a questão do nosso perfil, é um perfil bem aberto, procuramos conversar com todo mundo [...] nós visamos sempre àquele lado empreendedor que a gente tem, então daqui a pouco numa conversa informal pode surgir uma ideia e um negócio. E quanto a relações, a gente tem relações bem acentuadas com duas empresas aqui incubadas, é bem interessante (Gestor software).

Foi possível perceber práticas de relacionamentos e interações em processo de sedimentação entre empresas associadas e incubadas, como no caso das empresas marcas e aferição. Isso indica que, além dos processos formais e informais, alguns laços tendem a se fortificar mediante a trajetória dessas empresas, como se destaca no relato transcrito a seguir:

Tenho relacionamento com duas empresas, é a " $X$ " eu já tive algum contato com eles e, quando eu entrei aqui, a " $X$ " ainda estava aqui, eles estavam meio que se graduando, então já estavam começando a sair, já eram graduados, mas estavam aqui saindo. Então eu tive contato com eles e hoje quando a gente se encontra; eu vejo eles muito menos porque eles ficam no prédio ao lado, então não consigo ter muita interação com eles. E da aferição, que o "Fulano" é o dono, eu tenho mais contato porque eu faço alguns trabalhos para eles (Gestor marcas).

Também é interessante ressaltar que há interações e relacionamentos entre empreendedores que datam de períodos anteriores à formação da VALETEC e da ITEF. Esses relacionamentos são comuns entre alguns empreendedores associados e incubados, em que questões relacionadas com as atividades empresariais dos empreendedores são discutidas e soluções são propostas. A esse respeito, cabe destacar o seguinte relato:

Tem um grupo chamado grupo Quatro Colônias que é formado até antes da VALETEC, na época em que aqui essa região era uma zona industrial. Esse grupo de empresários então sempre se junta para desenvolver soluções em conjunto para todo mundo. Hoje eu sou presidente do grupo Quatro Colônias, e algumas empresas da VALETEC, mais o entorno aqui da RS-239 fazem parte desse grupo. Então a gente tem um relacionamento direto, aberto e mensal, inclusive com o poder público também (Gestor peças).

No Quadro 3, apresenta-se a síntese das percepções dos gestores das empresas incubadas e associadas, bem como uma relação entre essas percepções e os aspectos teóricos de CSO e CDs. Como observado anteriormente, em termos de complementariedades entre CSO e CDs, a trajetória tem o papel de potencializar os benefícios que as empresas podem obter via CSO. Nesse sentido, mesmo que diversas empresas possam estar desenvolvendo e compartilhando recursos e capacidades, via relacionamentos e interações, o ganho e o uso desses recursos e dessas capacidades podem ser diferenciados, dependendo da habilidade desenvolvida pelas empresas ao longo do tempo.

\begin{tabular}{|c|c|c|}
\hline \multicolumn{2}{|r|}{ Aspectos observados } & Aspectos teóricos \\
\hline \multirow[t]{3}{*}{$\mathrm{CSO}$} & $\begin{array}{l}\text { Relacionamento entre empresas via inte- } \\
\text { rações formais e informais. }\end{array}$ & $\begin{array}{l}\text { O capital social engloba a rede de relacionamen- } \\
\text { tos e os recursos por ela gerados e compartilha- } \\
\text { dos (NAHAPIET: GHOSHAL 1998). }\end{array}$ \\
\hline & $\begin{array}{l}\text { Compartilhamento de experiências e de } \\
\text { conhecimento e desenvolvimento de no- } \\
\text { vos negócios. }\end{array}$ & $\begin{array}{l}\text { O CSO é visto como recurso, refletindo as ações } \\
\text { coletivas e a visão compartilhada (LEANA; VAN } \\
\text { BUREN, 1999), disponibilizando acesso a recursos } \\
\text { e novas oportunidades para as organizações (AR- } \\
\text { REGLE et al.,2007). }\end{array}$ \\
\hline & $\begin{array}{l}\text { Características dos gestores atuam como } \\
\text { facilitador dos relacionamentos e das in- } \\
\text { terações. }\end{array}$ & $\begin{array}{l}\text { Boa vontade e relações de confiança remetem } \\
\text { aos aspectos de associabilidade e confiança (LE- } \\
\text { ANA; VAN BUREN, 1999; ARREGLE et al., 2007), }\end{array}$ \\
\hline
\end{tabular}




\begin{tabular}{|c|c|c|}
\hline \multicolumn{2}{|r|}{ Aspectos observados } & Aspectos teóricos \\
\hline CDs & $\begin{array}{l}\text { Desenvolvimento de recursos e de capa- } \\
\text { cidades para explorar oportunidades de } \\
\text { mercado e de editais. }\end{array}$ & $\begin{array}{l}\text { As CDs refletem a habilidade da empresa em } \\
\text { desenvolver recursos e capacidades ao longo do } \\
\text { tempo, identificando oportunidades e operando } \\
\text { no conjunto de recursos e capacidades, visan- } \\
\text { do explorar as oportunidades (TEECE; PISANO; } \\
\text { SHUEN, 1997; HELFAT; PETERAF, 2003; HARRELD; } \\
\text { O'REILLY W: TUSHMAN, 2007). }\end{array}$ \\
\hline \multirow[t]{3}{*}{$\begin{array}{l}\text { CSO } \\
\text { e CDs }\end{array}$} & $\begin{array}{l}\text { Busca de recursos e de capacidades com- } \\
\text { plementares via formação e fornecedores. }\end{array}$ & $\begin{array}{l}\text { O CSO é uma fonte de recursos e de capacida- } \\
\text { des acessada via relações com agentes externos } \\
\text { (ARREGLE et al., 2007; SIRMON; HITT; IRELAND, } \\
\text { 2007). O comprometimento da empresa com } \\
\text { agentes externos, como, por exemplo, com forne- } \\
\text { cedores, pode ser considerado como uma fonte } \\
\text { de desenvolvimento de capacidades (TEECE; PI- } \\
\text { SANO; SHUEN, 1997). }\end{array}$ \\
\hline & $\begin{array}{l}\text { Desenvolvimento de capacidades comple- } \\
\text { mentares via parcerias. }\end{array}$ & $\begin{array}{l}\text { Relacionamentos e interações como fonte de de- } \\
\text { senvolvimento de recursos e capacidades (ALSOS } \\
\text { et al., 2007; BLYLER; COFF, 2003; EISENHARDT; } \\
\text { MARTIN, 2000). }\end{array}$ \\
\hline & $\begin{array}{l}\text { Fortalecimento de interações ao longo da } \\
\text { trajetória das empresas. }\end{array}$ & $\begin{array}{l}\text { O CSO é um importante recurso intangível de- } \\
\text { senvolvido ao longo do tempo (ZAHRA, 2010). As } \\
\text { empresas podem aproveitar de forma diferente } \\
\text { as potencialidades do CSO, dependendo do tipo } \\
\text { de habilidade que elas desenvolveram ao longo } \\
\text { do tempo (NAHAPIET; GHOSHAL, 1998; HARRELD; } \\
\text { O'REILLY III; TUSHMAN, 2007) }\end{array}$ \\
\hline
\end{tabular}

Quadro 3: Síntese da percepção dos gestores das empresas incubadas e associadas

Fonte: elaboração própria

De acordo com a análise dos dados, como sintetizado no Quadro 3, as interações informais entre as empresas e o compartilhamento de conhecimentos e experiências são os aspectos mais significativos do CSO neste caso. Cabe destacar que as características pessoais dos gestores podem facilitar o desenvolvimento de CSO entre as empresas. De certa forma, essas evidências remetem à lógica de capital social gerencial. Como destacam Adner e Helfat (2003), os gestores podem, por meio do capital social, ampliar seu desempenho gerencial pelo acesso a informações.

No que tange às CDs, as evidências apontam para a necessidade de desenvolvimento de recursos e de capacidades para explorar as oportunidades de mercado. Nesse sentido, o CSO atua como uma das fontes de recursos e de capacidades adicionais por meio dos fornecedores e de parcerias e pelos relacionamentos desenvolvidos ao longo da trajetória das organizações. Nesse sentido, tais evidências remetem à visão relacional preconizada por Dyer e Singh (2008), em que os relacionamentos desenvolvidos ao longo do tempo podem fornecer vantagens, até mesmo competitivas, para as organizações.

\section{CONSIDERAÇÕES FINAIS}

O objetivo central deste trabalho foi compreender a relação entre CDs e CSO no ambiente de incubadora e parque tecnológico. Para tal, foi desenvolvido um estudo de caso exploratório com abordagem qualitativa no parque tecnológico da VALETEC e na ITEF.

Sob a ótica dos gestores do VALETEC e da ITEF, as empresas desenvolvem recursos e capacidades para explorar oportunidades por meio do apoio oferecido por esses agentes para o desenvolvimento de capacitação de gestão e de processos internos. Na lógica das CDs, os processos internos e as capacitações são centrais para a implementação de estratégias e para explorar oportunidades de mercado (TEECE, PISANO; SHUEN, 1997; AMBROSINI; BOWMAN, 2009; 


\section{TONDOLO; BITENCOURT, 2014).}

Esse aspecto remete aos processos de sensing e seizing, uma vez que é necessário alterar e/ou desenvolver um conjunto de recursos e capacidades para explorar as oportunidades identificadas (HODGKINSON; HEALEY, 2011; TEECE, 2012). Nesse ponto, uma possível complementariedade entre CSO e CDs pode ser destacada.

O CSO pode ser uma fonte de identificação de oportunidades, contribuindo ao processo de sensing. Da mesma forma, o CSO pode ser visto como fonte de acesso a recursos e capacidades necessárias para explorar as oportunidades identificadas, contribuindo para o processo de seizing. Sendo assim, é possível afirmar que a contribuição das CDs consiste em sua própria essência, pois tornam a empresa hábil a desenvolver esses processos de forma continuada ao longo do tempo.

Além disso, foi possível observar que o VALETEC e a ITEF atuam como agentes de promoção do desenvolvimento de relações, oportunizando ambientes de interação social dentro das empresas e entre estas e agentes externos, como outras empresas, universidades e governo. Essa relação entre órgãos de apoio e empresa é central para os gestores complementarem e até mesmo superarem carências de recursos e de capacidades (LIMA et al., 2009). Para o CSO, esses aspectos remetem à dimensão estrutural (NAHAPIET; GOSHAL, 1998; TSAl; GOSHAL, 1998; LEANA; VAN BUREN, 1999).

Já de acordo com a visão dos gestores das empresas associadas e incubadas, estas desenvolvem recursos e capacidades para explorar oportunidades por meio da busca de recursos físicos, financeiros e humanos, fomentando conhecimentos, desenvolvimento de novas parcerias e implementação de novas tecnologias. Como destacam Mello, Machado e Ferreira de Jesus (2010), as relações interorganizacionais podem ser consideradas uma forma de ampliar o nível de inovação das organizações, como, por exemplo, por meio da troca de experiências, conhecimentos e informações.

Esses aspectos remetem ao papel dos recursos e das capacidades desenvolvidas ao longo da trajetória da organização, como preconizado pela literatura das CDs (EISENHARDT; MARTIN, 2000), e à a dimensão estrutural, conforme proposto pela literatura de CSO (NAHAPIET; GOSHAL, 1998; TSAI; GOSHAL, 1998; LEANA; VAN BUREN, 1999). Cabe destacar, ainda, que o CSO pode ser considerado como dependente da trajetória, já que é solidificado ao longo do tempo (ZAHRA, 2010).

De acordo com o CSO, os relacionamentos e laços podem ser compreendidos a partir da dimensão estrutural (NAHAPIET; GOSHAL, 1998; TSAl; GOSHAL, 1998). Já as interações e o compartilhamento de recursos entre as empresas são compreendidos pela dimensão cognitiva do CSO (NAHAPIET; GOSHAL, 1998; TSAl; GOSHAL, 1998).

Pela lógica das CDs, os relacionamentos também são vistos como fonte de desenvolvimento de recursos e capacidades (ALSOS et al., 2007; EISENHARDT; MARTIN, 2000). Os laços formados pelo CSO são, também, considerados fontes de desenvolvimento de recursos e capacidades pelas CDs (BLYLER; COFF, 2003).

No entanto, é possível destacar uma relação central entre CSO e CDs: o desenvolvimento de habilidades das empresas em explorar e oportunizar a utilização do capital social e dos recursos compartilhados. Assim, pode haver diferenças na forma em que as empresas se valem do CSO, dependendo do nível de habilidades que essas organizações desenvolveram ao longo do tempo (NAHAPIET; GHOSHAL, 1998; HARRELD; O'REILLY III; TUSHMAN, 2007).

Cabe destacar que também foram observados elementos de associabilidade e confiança (LEANA; VAN BUREN, 1999). Foram identificadas, por exemplo, barreiras ao processo de intera- 
ção entre as empresas, especialmente pela falta de confiança entre uma empresa e outra. De forma oposta, algumas características dos gestores, como buscar e compartilhar conhecimentos, proporcionado uma abertura em relação a outras empresas, facilita o desenvolvimento de relacionamentos e interação.

Nesse sentido, é possível potencializar os possíveis ganhos do CSO por meio da qualidade das relações, remetendo à habilidade dos gestores em se relacionar (PASTORIZA; ARIÑO; RICART, 2009; LEANA; VAN BUREN, 1999) e à habilidade em utilizar essas relações e os recursos delas provenientes ao longo do tempo (NAHAPIET; GHOSHAL, 1998; HARRELD; O'REILLY III; TUSHMAN, 2007). Dessa forma, o CSO pode ser considerado como recurso e também como fonte de recursos organizacionais.

Portanto, a habilidade em interagir, potencializando as interações entre as empresas, pode ser destacada como mais uma relação entre CDs e CSO. Esse fato requer novos estudos acerca das diferenças entre as empresas no que tange à abertura para compartilhamento de experiências, aprendizados e desenvolvimento de projetos em conjunto e acerca do papel das habilidades desenvolvidas ao longo da trajetória da organização, por exemplo. Outros estudos futuros também podem analisar os níveis de CSO e CDs e o efeito destes no desempenho das organizações, investigando a influência do capital social gerencial e da visão relacional.

Por fim, destacam-se as limitações desta pesquisa no que se refere à sua capacidade de generalização e à necessidade de conhecer a visão de outras empresas (incubadas e associadas), bem como de outros parques tecnológicos e incubadoras, uma vez que nem todas as empresas, parques e incubadoras foram entrevistados. Isso permitira cruzar as percepções de membros internos e externos ao objeto foco deste estudo.

\section{REFERÊNCIAS}

ACQUAAH, M. Managerial social capital, strategic orientation, and organizational performance in an emerging economy. Strategic Management Journal, v. 28, p. 12351255, 2007.

ADLER; P. S.; KWON, S. Social capital: prospects for a new concept. Academy of Management Review, v. 27, n. 1, p. 17-40, 2002.

ADNER, R.; HELFAT, C. R. Corporate effects and dynamic managerial capabilities. Strategic Management Journal, v. 24, p. 1011-1025, 2003.

ALSOS, G. A. et al. The dynamic capability concept and its operationalization. Proceedings of the Babson College Entrepreneurship Research Conference at IE Business School, held on 7 - 9 June in Madrid, Spain, 2007.

AMBROSINI, V.; BOWMAN, C. What are dynamic capabilities and are they a useful construct in strategic management? International Journal of Management Reviews, v. 11, n.1, p. 29-49, 2009.

ARREGLE, J. et al. The development of organizational social capital: attributes of family firms. Journal of Management Studies, v. 44, n. 1, p. 73-95, 2007.

BARNEY, J. Firm resources and sustained competitive advantage. Journal of Management, v. 17, n. 1, p. 99-120, 1991.

Is the resource-based "view" a useful perspective for strategic management research? yes. Academy of Management Review, v. 26, n. 1, p.41-56, 2001.

BARNEY, J.; ARIKAN, A. M. The resource-based view: origens e implications. In: HITT, M. et al. (Ed.). Strategic entrepreneurship: creating a new mindset. 3. ed. Malden: Blackwell, p. 124188, 2005.

BESANKO, D.; et al. A economia da estratégia. 3.ed. Porto Alegre: Bookman, 2006. 
BLYLER, M.; COFF, R. W. Dynamic capabilities, social capital, and rent appropriation: ties that split pies. Strategic Management Journal, v. 24, p. 677-686, 2003.

BOLINO, M. C.; TURNLEY, W. H.; BLOODGOOD, J. M. Citizenship behavior and the creation of social capital in organizations. Academy of Management Review, v. 27, n. 4, p. 505-522, 2002.

COLLIS, D. J.; MONTGOMERY, C. A. Competing on resources. Harvard Business Review, v. 37, n. 4, p. 118-128, 1995.

CRAIG, J. C.; GRANT, R. M. Gerenciamento estratégico. São Paulo: Littera Mundi, 1999.

CRESWELL, J. W. Research design: qualitative, quantitative and mixed methods aproaches. 2. ed. Thousand Oaks: Sage, 2003.

DESS, G. G.; LUMPKIN, G. T. Emerging issues in strategy process research. In: HITT, $M$. A.; FREEMAN, R. E.; HARRISON, J. S. (ed.) Handbook of Strategic Management. Malden, MA: Blackwell Publishing, 2006, p. 3-34.

DYER, J.; SINGH, $H$. The relational view: cooperative strategy and sources of interorganizational competitive advantage. Academy of Management Review, v. 23, n. 4, p. 660-679, 1998.

EDELMAN, L. F. et al. The benefits and pitfalls of social capital: empirical evidence from two organizations in the United Kingdom. British Journal of Management, v. 15, p. 59-69, 2004.

EISENHARDT, K. M.; MARTIN, J. A. Dynamic capabilities: what are they? Strategic Management Journal, v. 21, p. 1105-1122, 2000.

EISENHARDT, K. M. Builnding theories from case study research. Academy of Management Review, v. 14, n. 4, p. 532-550, 1989.

FLICK, U. Uma introdução à pesquisa qualitativa. 2. ed. Porto Alegre: Bookman,
2004.

HARRELD, B.; O'REILLY III, C. A.; TUSHMAN, M. L. Dynamic capabilities at IBM: driving strategy into action. California Management Review, v. 49, n. 4, p.21-44, 2007.

HELFAT, C. E.; PETERAF, M. The dynamic resource-based view: capability lifecycles. Strategic Management Journal, v. 24, p. 9971010, 2003.

GIBBS, G. Análise de dados qualitativos. Porto Alegre: Artmed, 2009.

HENDERSON R. M. Managing innovation in the information age. Harvard Business Review, v. 72, n.1, p.100-106, 1994.

HODGKINSON, G. P.; HEALEY, M. P. Psychological foundations of dynamic capabilities: reflexion and reflection in strategic management. Strategic Management Journal, v. 32, p. 15001516, 2011.

INKPEN, A. C.; TSANG, E. W. K. Social capital, network, and knowledge transfer. Academy of Management Review, v. 30, n.1, p.146-165, 2005.

LEANA, C. R.; VAN BUREN, H. J. Organizational social capital and employment practices. Academy of Management Review, v. 24, n. 3, p. 538-555, 1999.

$\therefore$ PIL, F. K. Social capital and organizational performance: evidence from urban public schools. Organization Science, v. 17, n. 3, p. 353-366, 2006.

LIMA, E.; et al. Foco na inovação e complementaridade em equipes de direção no desenvolvimento de novas empresas tecnológicas. Revista de Administração da Universidade Federal de Santa Maria, v. 2, n. 2, p. 343-357, 2009.

LOBOSCO, A.; MORAES, M. A. de; MACCARI, E. A. Inovação: uma análise do papel da agência USP de inovação na geração de propriedade 
intelectual e nos depósitos de patentes da Universidade de São Paulo. Revista de Administração da Universidade Federal de Santa Maria, v. 4, n. 3, p. 406-424, 2011.

MAKADOK, R. Toward a synthesis of the resource-based and dynamic-capability views of rent creation. Strategic Management Journal, v. 24, p. 387 - 401, 2001.

MCGUINNESS, T.; MORGAN, R. E. Strategy, dynamic capabilities and complex science: management rhetoric vs. reality. Strategic Change, v. 9, p. 209-220, 2000.

MELLO, C. M. de ; MACHADO, H. V.; FERREIRA de JESUS, M. J. Considerações sobre a inovação em PMEs: o papel das redes e do empreendedor. Revista de Administração da Universidade Federal de Santa Maria, v. 3, n. 1, p. 41-57, 2010.

MORAN, P. Structural vs. Relational embeddedness: social capital and managerial performance. Strategic Management Journal, v. 26, p. 1129-1151, 2005.

NAHAPIET, J.; GHOSHAL, S. Social capital, intellectual capital and the organizational advantage. Academy of Management Review, v. 23, n. 2, p. 242-266, 1998.

PASTORIZA, D.; ARIÑO, M.; RICART, J. E. Drivers of organizational social capital in the firm: an empirical exploration. Academy of Management Proceedings, p.1-7, 2008.

PASTORIZA, D.; ARIÑO, M.; RICART, J. E. Creating an ethical work context: a pathway to generate social capital. Journal of Business Ethics, v. 88, p. 477-489, 2009.

PENNINGS, J. M.; LEE, K. Social capital of organization: conceptualization, level of analysis and performance implications. In: GABBAY, S.; LEENDERS, R. (ed.). Corporate Social Capital. 4. ed. New York: Addison Wesley, 1998.

PENROSE, E. T. Teoria del crescimiento de la empresa. Madrid: Aguilar, 1962.

SAPIENZA, H. J. et al. A capabilities perspective on the effects of early internationalization on firm survival and growth. Academy of Management Review, v. 31, n. 4, p. 914-933, 2006.

SCIT. Secretatia da Ciência, Inovação e Desenvolvimento Tecnológico. Disponível em: <http:// http://www.sct.rs.gov.br>. Acesso em: 23 nov. 2013.

SILVA, N. C. D. da; GIULIANI, A. C. Um estudo sobre o desenvolvimento no brasil da cooperação universidade-empresa - interação entre a instituição de ensino superior de tecnologia e a micro e pequena empresa. Revista de Administração da Universidade Federal de Santa Maria, v. 2, n. 3, p. 479-498, 2009.

SIRMON, D. G; HITT, M. A.; IRELAND, R. D. Managing firm resources in dynamic environments to creste value: looking inside the black box. Academy of Management Review, v. 32, n.1, p. 273-292, 2007.

STAKE, R. Investigación con estudio de casos. Madrid: Ediciones Morata, 1998.

TEECE, J.; PISANO, G.; SHUEN, A. Dynamic capabilities and strategic management. Strategic Management Journal, v. 18, n. 7, p. 509-533, 1997.

TEECE, J.; Explicating dynamic capabilities: the nature and microfoundations of (sustainable) enterprise performance. Strategic Management Journal, v. 28, n. 7 , p. 13191350, 2007.

Dynamic capabilities: routines versus entrepreneurial action. Journal of Management Studies, p. 1-8. 2012.

TONDOLO, V. A. G.; BITENCOURT, C. C. Compreendendo as capacidades dinâmicas a partir de seus antecedentes, processos e resultados. Brazilian Business Review, v. 11, n. 
5, p. 124-147, 2014.

TSAI, W.; GHOSHAL, S. Social capital and value creation: the role of intrafirm networks. Academy of Management Journal, v. 41, n. 4, p. 464-476, 1998.

Social capital, strategic relatedness and the formation of intraorganizational linkages. Strategic Management Journal, v. 21, p. 925-939, 2000.

ZAHRA, S. A. Harvesting family firm's organizational social capital: a relational perspective. Journal of Management Studies, v. 47, n. 2, p. 345-366, 2010.

ZOLLO, M.; WINTER, S. G. Deliberate learning and the evolution of dynamic capabilities. Organization Science, v. 13, n. 3, p. 339-351, 2002.

ZOTT, C. Dynamic capabilities and the emergence of intraindustry differential firm performance: insights from a simulation study. Strategic Management Journal, v. 24, p. 97125, 2003.

WANG, C. L.; AHMED, P. K. Dynamic capabilities: $A$ review and research agenda. International Journal of Management Reviews, v. 9, n.1, p. 31-51, 2007.

YIN, R. K. (2001). Estudo de caso: planejamento e métodos. 2. ed. Porto Alegre: Bookman, 2001.

Os autores agradecem ao apoio recebido do CNPQ.

Os autores também agradecem às sugestões dos avaliadores, que qualificaram este trabalho. 